\title{
RANCANGAN PENGELOLAAN INTERAKSI MEDIA SOSIAL SELASAR SUNARYO ART SPACE KOTA BANDUNG
}

\author{
Audris Shafitama* \\ Sekolah Tinggi Pariwisata Bandung \\ audrisshftm@gmail.com \\ Nurdin Hidayah \\ Sekolah Tinggi Pariwisata Bandung \\ nurdin@stp-bandung.ac.id \\ Suteja Wira Dana Kusuma \\ Sekolah Tinggi Pariwisata Bandung \\ suteja.wiradanakusuma@gmail.com
}

\begin{abstract}
This study aims to design the management of social media interactions at Selasar Sunaryo Art \& Space. The method used in this research is descriptive with a qualitative approach. While the data collection techniques used were interviews and observations, which later the results would be analyzed using the Miles \& Huberman analysis model and tested for their validity using source triangulation. The results show that the lack of interaction on social media from Selasar Sunaryo Art \& Space is due to the absence of a special division that handles social media, which causes the quality and quantity of human resource capacity in managing social media not yet optimal. For this reason, Selasar Sunaryo Art \& Space is advised to form a special division that handles social media and creates content that can establish interactions with the audience.
\end{abstract}

Keywords: digital marketing, social media marketing, Selasar Sunaryo Art \& Space.

\begin{abstract}
Abstrak
Penelitian ini bertujuan untuk merancang pengelolaan interaksi media sosial di Selasar Sunaryo Art \& Space. Metode yang digunakan dalam penelitian ini adalah deskriptif dengan pendekatan kualitatif. Sedangkan teknik pengumpulan data yang digunakan adalah wawancara dan observasi, yang nanti hasilnya akan dianalisis menggunakan model analisis Miles \& Huberman dan diuji keabsahannya menggunakan triangulasi sumber. Hasil penelitian menunjukan bahwa kurangnnya interaksi di sosial media dari Selasar Sunaryo Art \& Space dikarenakan belum adanya divisi khusus yang menangani sosial media, yang menyebabkan kualitas dan kuantitas kapasitas sumber daya manusia dalam mengelola sosial media belum cukup optimal. Untuk itu Selasar Sunaryo Art \& Space disarankan untuk membentuk divisi khusus yang menangani sosial media dan membuat konten-konten yang dapat menjalin interaksi dengan audiens (khalayak).
\end{abstract}

Kata kunci: digital marketing, social media marketing, Selasar Sunaryo Art \& Space

\section{A. PENDAHULUAN}

Menurut data statistik yang ditampilkan oleh Hootsuite bersumber dari Global Web Index, jumlah pengguna media sosial tercatat pada tahun 2018 adalah 3,196 miliar orang dengan kenaikan pengguna sebesar $13 \%$ setiap tahunnya. Indonesia menjadi salah satu negara yang pertumbuhan pengguna media sosialnya pesat, yaitu 23\% pertahun dengan rata-rata orang menghabiskan 6 jam perhari berselancar di dalamnya. Arti dari sosial sendiri menurut O’Reilly (2005:61) adalah alat untuk berbagi dan berdiskusi 
tentang informasi yang tersedia secara dua arah. Informasi yang tersebar di media sosial pun sangat beragam dan terkemas dalam berbagai jenis bentuk konten seperti foto, video, tulisan, hingga podcast. Media sosial pun kini menjadi salah satu alat pemasaran, dimana perannya dapat memudahkan orang untuk terhubung secara sosial namun disaat yang bersamaan para pemangku usaha atau pengelola destinasi wisata mendapatkan keuntungan. Peran media sosial sebagai alat pemasaran tidak akan maksimal jika hal tersebut tidak dikelola dengan baik. Dalam mengelola media sosial sebagai salah satu alat pemasaran, dapat dibentuk dengan beberapa acuan yang di dalamnya terdapat beberapa aspek seperti: tujuan pengelola, interaksi, kunjungan berulang, jumlah followers, jumlah mention, hasil pencarian di media sosial pemilik akun dan rekomendasi antara pengunjung. Untuk membatasinya, Paine (2016:2) mengatakan bahwa dalam mengelola sebuah media sosial dapat menggunakan interaksi sebagai aspek utamanya. Interaksi tersebut dapat berupa likes, comments, followers dan hashtag. Di tengah maraknya pengguna media sosial saat ini, Selasar Sunaryo yang sudah berdiri selama 20 tahun dan memiliki semua jenis media sosial sejak bertahun-tahun yang lalu tidak begitu menunjukkan interaksi yang signifikan. Hal tersebut dapat dilihat dari sedikitnya jumlah komentar, likes, penggunaan hashtag (tagar) dan pengikut dalam semua media sosial mereka. Melihat dari keinginan Selasar Sunaryo untuk menjangkau audiens yang lebih luas ke depannya, maka interaksi dalam media sosialnya harus dikelola dengan baik. Sebuah interaksi dalam media sosial menurut Roope Jaakonmaki, Jan vom Brocke dan Oliver Muller (2016:2), dapat dibentuk dengan 3 fokus besar yaitu creator-related features, contextual features dan content features. Hal ini yang akan digunakan untuk mengelola interaksi media sosial Selasar Sunaryo. Oleh karena hal tersebut, tujuan diadakannya penulisan jurnal ini adalah untuk membuat rancangan pengelolaan interaksi media sosial Selasar Sunaryo. Sehingga nantinya, Selasar Sunaryo di media sosial dapat menjangkau audiens yang lebih luas.

\section{B. KAJIAN LITERATUR}

\section{Marketing Communication}

Komunikasi pemasaran adalah sebuah proses dimana pengelola memiliki interaksi dengan audiens. Kata kunci dalam komunikasi pemasaran ini adalah untuk menciptakan sebuah interaksi (engagement), untuk menggandeng audiens yang bermacam-macam sesuai dengan kebutuhan mereka saat menentukan produk apa yang ingin mereka beli (Fill dan Jemieson, 2014; Hidayah, 2019).

\section{Pengelolaan Interaksi Media Sosial}

Roope Jaakonmaki, Jan vom Brocke dan Oliver Muller (2016:2) yaitu:

1. Creator-Related Feature yang di dalamnya menitik beratkan kepada pemangku usaha, yang berisikan seperti apa profil media sosial Selasar Sunaryo. Isinya mencakup jumlah pengikut, lamanya admin mengelola media sosial, bagaimana admin melakukan interaksi dengan audiens dan target yang ingin dicapai.

2. Contextual Feature, yang di dalamnya dibagi lagi menajdi empat indikator lain yaitu sharing, conversation, presence dan time.

3. Content Feature, yang mana harus diteliti tentang jenis konten seperti apa yang paling disukai oleh pengguna media sosial. Hal ini akan menentukan foto, video dan teks seperti apa yang paling digemari pengguna.

34 | Barista: Jurnal Kajian Bahasa dan Pariwisata, Volume 6 Nomor 1, 2019: 33-38 


\section{METODE PENELITIAN}

Metode yang digunakan dalam penelitian ini adalah metode penelitian deskriptif dengan pendekatan kualitatif. Penelitian deskriptif secara garis besar bertujuan untuk menggambarkan data atau masalah yang diteliti secara cermat, Silalahi (1999:51). Ada pun partisipan dalam penelitian ini adalah project manager, admin media sosial dan pengunjung Selasar Sunaryo. Sementara tempat penelitian ini berlangsung adalah Selasar Sunaryo Art Space yang bertempat di Jl. Bukit Dago Timur No. 100, Kota Bandung. Teknik pengumpulan data dalam penelitian ini adalah wawancara yang dibantu dengan alat bantu rekam serta pedoman wawancara serta observasi media soisalnya. Seluruh data yang sudah didapatkan melalui wawancara akan dianalisis menggunakan teknik model Miles dan Huberman (1984). Tahap-tahap yang dilakukan dalam menganalisis data ini adalah data reduction, data display dan conclusion drawing / verification. Selanjutnya, hasil analisis tersebut akan diuji keabsahannya menggunakan triangulasi sumber yang menurut Patton dalam Moleong (1999:178) berarti membandingkan dan mengecek ulang derajat kepercayaan data yang diperoleh.

\section{HASIL PENELITIAN}

Creator Related Feature : Media sosial yang dimiliki Selasar Sunaryo adalah facebook, twitter, imstagram, website dan youtube walaupun tidak semuanya di update secara rutin. Kini, pengelola media sosial Selasar Sunaryo dibagi menjadi tiga bagian, yang pertama adalah Project Manager sebagai pemegang utama instagram sekaligus orang yang pertama kali membuatnya, kedua adalah admin yang merangkap front office untuk mengelola facebook, twitter, e-mail dan youtube, yang ketiga adalah orang IT sebagai admin yang mengelola website. Sejauh ini, konten yang memiliki engagement atau interaksi paling banyak dalam media sosialnya menurut kedua partisipan adalah konten tentang Pak Sunaryo dan event besar, contohnya pameran ulang tahun Selasar Sunaryo ke-20 di tahun 2018 kemarin. Target utama yang ingin dicapai menurut project manager dan admin adalah followers di Instagramnya mencapai 10.000. Target berikutnya yang dijabarkan oleh project manager adalah, pengelola ingin lebih sering memposting konten yang tidak hanya tentang promosi program saja namun juga konten tentang Pak Sunaryo. Pengelola pun ingin mempunyai divisi khusus untuk menangani media sosial sekaligus menghandle adminnya sehingga Selasar Sunaryo di kemudian hari dapat lebih fokus mengelola media sosialnya.

Context Related Feature: Dalam mengelola media sosialnya, Selasar Sunaryo sudah memiliki jadwal rutin untuk memposting dua kontennya yaitu Arsip Selasar dan Pustaka Selasar. Kedua konten tersebut dibagikan setiap hari Kamis, selama dua minggu sekali bergantian. Selasar Sunaryo tidak terlalu memperhatikan jumlah engagement paling banyak selama ini sehingga acuan memposting kontennya selama ini hanya hari Kamis saja. Berbeda dengan pengunjung, mereka tidak memperhatikan engagement dalam satuan hari, tapi mereka dapat menentukan waktu-waktu mana yang followers media sosialnya paling aktif. Waktu-waktu tersebut adalah saat istirahat, malam dari jam 6-9 dan hari libur. Kebanyakan pengunjung memposting pengalaman berkunjung ke Selasar Sunaryo di instagram story. Setiap update yang dilakukan oleh pengunjung pasti menggunakan tag lokasi Selasar Sunaryo atau men-tag media sosialnya Selasar Sunaryo. Menelisik tentang percakapan yang terjadi di media sosialnya, partisipan dari Selasar Sunaryo menjawab bahwa ternyata kebanyakan orang bertanya melalui direct message di instagram sementara di facebook dan twitter terhitung jarang. Biasanya pertanyaan yang terlontar dalam direct message adalah perihal pameran, penyewaan tempat, dsb. Sementara, keluhan yang diungkapkan orang-orang biasanya sebatas sistem bayar untuk masuk pameran. Sistem pembayaran untuk masuk ke pameran ini baru saja diaplikasikan dan disahkan tepat pada saat ulang tahun Selasar Sunaryo yang ke-20 di tahun 2018 kemarin. Melihat bagaimana eksistensi Selasar Sunaryo ini ditanyakan lewat penggunaan fitur advertisement yang ternyata selama bermedia sosial, Selasar Sunaryo belum pernah menggunakan 
fitur tersebut sama sekali, dikarenakan pembayarannya yang terhitung rumit karena menggunakan kartu kredit yang mana berarti harus ada akun khusus untuk melakukan pembayaran promosi ini. Oleh karena itu, jika Selasar Sunaryo memutuskan untuk tidak menggunakan fitur promosi, maka keaktifannya di media sosial butuh ditingkatkan entah dengan lebih rutin memposting konten di setiap media sosialnya atau lewat bantuan social media influencer untuk datang ke Selasar Sunaryo dan mempostingnya di media sosial sehingga Selasar Sunaryo akan diketahui oleh lebih banyak orang di internet.

Content Feature: Foto yang menarik bagi para pengunjung Selasar Sunaryo adalah foto yang warnanya tidak begitu berlebihan dan dapat dibuat senada atau seragam dalam media sosialnya sehingga ada level konsistensi disitu. Penggunaan filter gambar yang berlebihan tidak terlalu menarik menurut mereka. Pengunjung tidak begitu menghiraukan adanya manusia sebagai objek foto, yang penting pengambilan gambarnya bagus karena pengambilan ini pun berpengaruh. Mereka menyukai gambar yang bagus dengan komposisi angle bagus, pencahayaannya baik, momennya unik, serta ada isi atau pesan yang ingin disampaikan sehingga tidak asal memotret saja. Sementara untuk konten video atau audio visual, bisa dikatakan menarik jika dalam satu video mencakup seluruh kegiatan atau pesan yang ingin disampaikan secara keseluruhan. Hal itu membuat penonton dapat menonton satu video saja namun bisa mendapatkan seluruh pesan atau kegiatan yang ingin disampaikan oleh pembuat video. Sementara wadah yang paling cocok menurut mereka untuk membagikan konten video adalah Instagram, karena durasi video yang di posting tidak akan terlalu lama. Sebuah deskripsi yang menarik bagi para pengunjung adalah tulisan yang padat merinci tanpa bertele-tele, yang isinya informasi secara detail seperti deskripsi event, waktu, harga serta jam operasional. Hal itu berbanding lurus dengan penelitian yang dilakukan Roope Jaakonmaki, Jan vom Brocke dan Oliver Muller (2016:2) bahwa memang penggunaan kata-kata yang simpel dan tidak terlalu panjang akan lebih menarik orang-orang untuk melihat kontennya. Deskripsi pada media sosial tidak akan lengkap rasanya jika tidak ditambahkan tagar atau hashtag. Pada penelitian yang dilakukan oleh Fortune 500 yang ditampilkan pada jurnal mereka, postingan yang memiliki lebih dari 11 tagar mempunyai nilai interaksi lebih tinggi, sedangkan Selasar Sunaryo minim menggunakan tagar di setiap postingannya bahkan tidak ada \#SelasarSunaryo, padahal tagar adalah salah satu alat pencarian di media sosial. Penggunaan hashtag yang banyak memang mengurangi estetika sebuah deskripsi postingan, namun media sosial memiliki kolom komentar yang dapat digunakan untuk menaruh hashtag yang ingin digunakan, sehingga di deskripsi utama, hashtag tersebut tidak akan terlihat.

\section{E. SIMPULAN}

Sejauh ini, Selasar Sunaryo memiliki lima media sosial yang masih digunakan walaupun tidak begitu aktif penggunaannya. Pada kelima media sosial tersebut, ada tiga orang yang bekerja sebagai admin yang tidak hanya memposting konten saja namun merangkap tugas lain seperti front office, Project Manager, dsb. Oleh karena itu, harapan Selasar Sunaryo ke depannya adalah memiliki divisi khusus untuk mengelola media sosial agar media sosialnya akan lebih rajin di update. Kini target utama mereka adalah 10.000 followers di instagram.

Interaksi yang terjalin pada media sosial Selasar Sunaryo masih kurang, hal itu dilihat dari jumlah likes dan komentar di media sosialnya sehingga minim adanya percakapan disana. Walaupun begitu, pengunjung yang berkunjung kesana biasanya tetap update di media sosial mereka dengan tag lokasi di Selasar Sunaryo dan admin akan selalu berusaha me-repost ulang unggahan para pengunjung jika hal itu berbentuk instagram story. Sejauh ini, Selasar Sunaryo sudah memiliki jadwal rutin memposting konten, walaupun hal tersebut tidak didasari dengan jumlah interaksi terbanyak dalam seminggu. 
Konten foto yang menarik bagi pengunjung adalah foto yang tidak asal dipotret tanpa ada pesan atau momen unik di dalamnya. Pengambilan gambar pun berpengaruh, saat anglenya sesuai dan pencahayaannya cukup. Pemberian warna sebagai filter foto tidak perlu berlebihan, namun akan lebih bagus jika semua fotonya mempunyai warna yang senada sehingga terlihat level konsistensinya. Sementara video yang menarik bagi mereka adalah video yang memiliki pesan yang ingin disampaikan berdurasi tidak terlalu lama dengan warna dan musik yang disesuaikan. Tidak lengkap rasanya sebuah postingan tanpa deskripsi, namun dibutuhkan sebuah deskripsi yang menarik pula untuk mendorong orang-orang agar membaca. Deskripsi yang menarik adalah deskripsi yang informatif tanpa perlu banyak berbasa-basi sehingga dalam tulisan singkat padat, pengunjung dapat mengetahui informasi detail seperti deskripsi event, waktu, harga, jam operasional, dsb.

\section{Rekomendasi}

1. Membentuk Divisi Khusus Media Sosial

Tim khusus media sosial ini akan menjadi kreator konten mencakup foto, video, tulisan dan design untuk di publish pada setiap media sosial Selasar Sunaryo. Mereka tidak hanya membuat konten, namun juga mengolah konten pengunjung yang dibagikan di media sosial untuk nantinya di repost pada media sosial Selasar. Tidak hanya itu, tim media sosial ini sekaligus menjadi admin yang sedia memantau dan meng-update keadaan di Selasar Sunaryo setiap harinya.

Oleh karena itu, ada sumber daya manusia yang dibutuhkan dalam pembentukan tim media sosial ini. Beberapa orang yang memang ahli di bidangnya dan memiliki selera estetika yang baik dan sesuai dengan Selasar Sunaryo, yaitu orang yang menguasai software khusus desain baik foto atau video seperti software dari Adobe. Selanjutnya adalah orang social media marketing sehingga beliau mengerti tentang bagaimana seharusnya media sosial dikelola sekaligus dengan pengamatan engagement yang ada di setiap media sosial. Berikutnya adalah orang yang baik dalam copywriting yang tulisannya dapat satu identitas dengan Selasar Sunaryo.

2. Membuat Konten Wadah Bercakap antara Pengunjung dan Pengelola

Pembentukan momen baru untuk meningkatkan percakapan yang ada ini akan dinamakan Momen Selasar. Momen Selasar bertujuan untuk wadah sharing sekaligus bercakap di media sosial. Momen Selasar ini akan di posting pada instagram story, yang hanya bertahan 24 jam sehingga tidak ada yang akan terganggu dengan postingannya. Momen Selasar dibentuk dalam bentuk volume atau edisi, dimana satu volume membahas satu momen yang terjadi di Selasar Sunaryo, menggunakan template yang seragam sehingga orang-orang dapat lebih aware tentang hal ini. Nantinya, setiap volume dari Momen Selasar ini dibuatkan highlight sehingga orang-orang yang terlewat ikut diskusi dapat tetap melihat jawaban orang-orang lain di profil instagram Selasar Sunaryo. Otomatis hal tersebut dapat menambahkan jumlah interaksi di media sosial dalam bentuk percakapan dan menambahkan jumlah profile visit di profilnya.

3. Perbaikan Konten

Pertama pada instagram, ditambahkan highlights dengan judul Kopi Selasar.yang berisikan gambaran tempat Kopi Selasar, diikuti dengan instagram story pengunjung di Kopi Selasar entah berbentuk video atau foto. Berikutnya di twitter dibuatkan thread tentang Kopi 
Selasar, dimana admin memposting beberapa tweet dalam satu rangkai berisikan informasi range harga minuman serta makanan di Kopi Selasar, alamat dan foto-foto tempatnya.

Selanjutnya adalah penggunaan hashtag yang bertuliskan \#SelasarSunaryo \#KopiSelasar dan \#NamaPameran, disesuaikan dengan konten yang sedang di publish, namun untuk tagar \#SelasarSunaryo wajib digunakan di semua postingan di setiap media sosialnya mulai dari instagram, twitter, facebook hingga youtub

\section{DAFTAR PUSTAKA}

Fill, Chris and Jamieson, Barbara. 2014. Marketing Communications. Edinburgh : Edinburgh Business School.

Hidayah, Nurdin. (2019). Pemasaran Destinasi Pariwisata. Bandung: Alfabeta

Moleong, Lexi. 1999. Metode Penelitian Kualitatif. Bandung : PT. Remaja Rosdakarya.

O'Reilly, Tim. 2005. What Is Web 2.0? Sebastopol : O'Reilly Media.

Silalahi, Ulber. 1999. Metode dan Metodologi Penelitian. Bandung : Bina Budhaya.

The Impact of Content, Context, and Creator on User Engagement in Social Media Marketing. Jaakonmaki, Roope, Brocke, Jan vom and Muller, Oliver. 2016.

https://www.instagram.com/nuartpark/?hl=en (2019)

https://www.instagram.com/p/BxRWEs9gFTu/ (2019) 